\title{
Stress Sensitization of Ethanol Withdrawal-Induced Reduction in Social Interaction: Inhibition by CRF-I and Benzodiazepine Receptor Antagonists and a 5-HT/A-Receptor Agonist
}

\author{
George R Breese*,',2, Darin J Knapp', David H Overstreet' \\ 'Department of Psychiatry, School of Medicine, University of North Carolina, Chapel Hill, NC, USA; '2Department of Pharmacology, School of \\ Medicine, University of North Carolina, Chapel Hill, NC, USA
}

\begin{abstract}
Repeated withdrawals from chronic ethanol sensitize the withdrawal-induced reduction in social interaction behaviors. This study determined whether stress might substitute for repeated withdrawals to facilitate withdrawal-induced anxiety-like behavior. When two I-h periods of restraint stress were applied at I-week intervals to rats fed control diet, social interaction was reduced upon withdrawal from a subsequent 5-day exposure to ethanol diet. Neither this ethanol exposure alone nor exposure to three restraint stresses alone altered this measure of anxiety. Further, the repeatedly stressed singly withdrawn rats continued to exhibit a reduction in social interaction 16 days later, upon withdrawal from re-exposure to 5 days of chronic ethanol, consistent with a persistent adaptation by the multiple-stress/withdrawal protocol. Weekly administration of corticosterone in place of stress induced no significant change in social interaction upon withdrawal from the single chronic ethanol exposure, indicative that corticoid release is not responsible for the stressinduced reduction in anxiety-like behavior during withdrawal. In the multiple-withdrawal protocol, stress applied during withdrawal from voluntary ethanol drinking by P-rats facilitated ethanol drinking sufficiently, to induce a withdrawal-induced reduction in social interaction. Administration of a CRF-I receptor antagonist, a benzodiazepine receptor antagonist, or a 5-HTIA receptor agonist prior to each stress minimized sensitization of the withdrawal-induced reduction in anxiety-like behavior. Since these pharmacological consequences on the induction of anxiety-like behavior following the stress/withdrawal protocol are like those previously seen when these drug treatments were given prior to multiple withdrawals, evidence is provided that repeated stresses and multiple withdrawals sensitize the withdrawal reduction in social interaction by similar central adaptive mechanisms.
\end{abstract}

Neuropsychopharmacology (2004) 29, 470-482, advance online publication, 03 September 2003; doi: I 0.1038/sj.npp. 1300282

Keywords: restraint stress; chronic ethanol; social interaction; anxiety; corticotrophin-releasing factor; corticosterone

\section{INTRODUCTION}

Many clinical (Ballenger and Post, 1978; Brown et al, 1988; Malcolm et al, 2000a,b) and animal studies (Maier and Pohorecky, 1989; McCown and Breese, 1990; Becker and Hale, 1993; Kokka et al, 1993; Becker et al, 1997, 1998; Meert and Huysmans, 1994; Ulrichsen et al, 1998) support the concept that the increased seizure susceptibility following multiple withdrawals from chronic ethanol resembles a kindling process. Based upon the implication that symptoms of withdrawal other than seizure susceptibility also increase over time in alcoholics (Ballenger and Post, 1978), subsequent experiments showed that repeated withdrawals

*Correspondence: Dr GR Breese, Center For Alcohol Studies, 3007 Thurston-Bowles Building CB-7178, UNC School of Medicine, Chapel Hill, NC 27599-7I78, USA, Tel.: + I 919966 308I, Fax: + I 919966 5679, E-mail: george_breese@med.unc.edu

Received II April 2003; revised I0 June 2003; accepted I 3 June 2003 Online publication: 10 July 2003 at http://www.acnp.org/citations/ Npp07100303 I59/default.pdf from chronic ethanol diet over three periods of 5 days, with 2 days of withdrawal between cycles, reduced social interaction between 5 and $6 \mathrm{~h}$ after ethanol removal from the final ethanol exposure (Overstreet et al, 2002). Sensitization of anxiety-like behavior was not observed with withdrawal from continuous (noncycled) ethanol exposure. Consequently, this multiple-withdrawalinduced increase in anxiety-like behavior (Overstreet et al, 2002) provides strong support that a 'kindling' phenomenon could be relevant to symptoms other than seizures in alcoholics after absence from repeated ethanol exposures.

Stress reportedly increases the risk of relapse in alcoholics (Brown et al, 1990, 1995; Pohorecky, 1991; Sinha, 2001). Therefore, it was questioned whether repeated stresses could substitute for withdrawals in the multiple-withdrawal protocol to sensitize the withdrawal-induced reduction in social interaction after only a single withdrawal from 5 days of chronic ethanol exposure. As will be outlined, repeated stress applications decreased social interaction following 
withdrawal from the single chronic ethanol treatment. Since stress increases steroid release (Garcia and Armario, 2001), it was subsequently determined whether steroids could emulate the stress-induced increase in anxiety-like behavior, following withdrawal from chronic ethanol. Lê et al $(1998,2000)$ reported that priming doses of ethanol and exposures to stress reinstate alcohol-seeking behavior. Therefore, it was additionally tested whether stress administered during withdrawal from multiple voluntary drinking episodes in alcohol-preferring $\mathrm{P}$-rats would enhance drinking to a sufficient degree to enhance withdrawalinduced anxiety.

Stress also emulates several other aspects of chronic alcohol exposure and withdrawal, including an increase in activity of the HPA axis (stress: Kim et al, 2000; Garcia and Armario, 2001; alcohol: Rassnick et al, 1993; Rasmussen et al, 2000; Zorrilla et al, 2001), an increase in diazepambinding inhibitor in brain (stress: Ferrarese et al, 1991a,b, 1993; alcohol: Katsura et al, 1995a, b, 1998; Ohkuma et al, 2001), and influences on serotonergic activity (stress: Chaouloff et al, 1999; Fujino et al, 2002; Matuszewich et al, 2002; alcohol: Fils-Aime et al, 1996; Heinz et al, 2001). A drug affecting serotonin receptor function (ie a $5-\mathrm{HT}_{1 \mathrm{~A}}$ agonist; see Overstreet et al, 2003), a CRF-1 receptor antagonist (Knapp et al, 2001), and a benzodiazepine receptor antagonist (Knapp et al, 2001) given during the initial two withdrawals, but not the third, minimize the withdrawal-induced reduction in social interaction during the final withdrawal of the repeated withdrawal protocol. Owing to the similarities of stress and withdrawal from chronic ethanol on specific neural systems, the present effort examined the effect of these drugs, which were known to interfere with the sensitization of the decrease in social interaction seen with multiple withdrawals from chronic ethanol, on the stress sensitization of the withdrawalinduced reduction in social interaction.

\section{METHODS}

\section{Animals}

Male Sprague-Dawley rats (Charles-River, Raleigh, NC, USA) approaching 6 weeks of age (160-180 g) were initially housed in groups of 3 or 4 for several days to adapt to the animal facility conditions (light: dark cycle of $12: 12$, with lights on between 0900 and 2100 hours), before being individually housed and exposed to various control and ethanol-containing diets. Since Sprague-Dawley rats do not voluntarily drink an ethanol solution, male ethanolpreferring P-rats were included to allow investigation of repeated stresses on drinking behavior. These male P-rats were chosen from the breeding colony when they were of the same age and weight as the Sprague-Dawley rats. The Prats were housed individually in a room on a reversed light cycle (lights off from 1000 to 2200 hours) from that of the Sprague-Dawley rats, and exposed to a $10 \%$ ethanol solution and water (see below). All procedures described below dealing with chronic ethanol exposures and repeated applications of stress have been approved by the Institutional Animal Care \& Use Committee (IACUC) at the University of North Carolina.

\section{Ethanol and Control Diets}

When placed in individual cages, the rats received a lactalbumin-/dextrose-based nutritionally complete liquid diet (with concentrations of vitamins, minerals and other nutrients derived from ICN Research Diets) (eg Frye et al, 1983; Moy et al, 1997, 2000). Dextrose calories in the control diet (CD) were equated with calories for ethanol in the ethanol-containing diet. After 3 days of $C D$, a portion of the rats received a $4.5 \%(\mathrm{w} / \mathrm{v})$ ethanol diet administered for three cycles of 5 days interspersed with 2 days of CD. As a control, another group received the $4.5 \%$ ethanol diet continuously for 15 days. Other rats received CD for 2 weeks before receiving a single exposure to $4.5 \%$ ethanol diet for 5 days. In a portion of this latter group of animals exposed to CD followed by the $4.5 \%$ ethanol diet for 5 days, restraint stress (see below) was applied during the CD period at times when other rats were experiencing the initial two withdrawals of the multiple-withdrawal protocol. A modified pair-feeding design was used, which involved administering a volume of $\mathrm{CD}$ equivalent to the average volume consumed the previous day by the rats maintained on ethanol diet. The rats were weighed at weekly intervals to establish similar body weights in the groups.

In the voluntary ethanol-drinking experiments, the P-rats were initially exposed to 3 days of ethanol solution $(10 \%$ v/v) with no water present, but with food present at all times. Subsequently, one P-rat group was allowed continuous exposure to a choice of either ethanol $(10 \% \mathrm{w} / \mathrm{v})$ or water for 15 days. The other P-rats were withdrawn from three 5-day exposures to a $10 \%$ ethanol solution or water with 2 days of abstinence (withdrawal) between the initial two cycles of ethanol presence. A portion of the cycled rats was exposed to restraint stress as outlined below. The amount of ethanol solution consumed was recorded daily for each group. To illustrate the change in voluntary ethanol drinking in the groups, the cumulative ethanol intake over the first 5 days was taken as baseline, and this level of ethanol intake was subtracted from the cumulative intake over the second and third 5-day cycles of ethanol drinking. Social interaction was measured $5-6 \mathrm{~h}$ after withdrawal from the third cycle of voluntary drinking of the ethanol solution.

\section{Stress Application}

In order to evaluate the effect of stress on social interaction after a single withdrawal from chronic ethanol, animals were exposed to restraint stress to substitute for the initial two withdrawals of the multiple-withdrawal protocol. This stress procedure involved placing rats in a wire mesh conical tube $(20 \mathrm{~cm}$ in length and $9 \mathrm{~cm}$ at the opening) for $1 \mathrm{~h}$ at 6 and 11 days while on control-liquid diet. The single exposure to $4.5 \%$ ethanol diet for 5 days was initiated $24 \mathrm{~h}$ after the final stress application. Additionally, the effect of two or three stresses alone on social interaction was determined.

The effect of multiple withdrawals and stresses on the choice of ethanol or water drinking in P-rats was also assessed, utilizing the repeated-withdrawal protocol, as described above (Overstreet et al, 2002). To make this determination, restraint stress was applied to some P-rats 
between 4 and $5 \mathrm{~h}$ after removal of the ethanol during the first and second periods of ethanol withdrawal, while the other P-rats undergoing the multiple-withdrawal protocol did not receive this challenge. During the final period of withdrawal $(5 \mathrm{~h})$ from ethanol exposure, social interaction was measured for each group of P-rats.

\section{Social Interaction Test after Repeated Stresses and Withdrawals}

Time spent in social interaction (as a measure of anxietylike behavior) and number of line crosses (as a measure of general activity level) by the rats was assessed. The social interaction test, first introduced by File and Hyde (1978), has been validated to measure anxiety-like behavior in many investigations (File and Hyde, 1978; File, 1980, 1993; File and Lister, 1984; Guy and Gardner, 1985; File et al, 1989, 1993; Lightowler et al, 1994; Sams-Dodd, 1995; Andrews et al, 1997; Bhattacharya et al, 1997; Irvine et al, 2001). The social interaction testing was carried out in a square open field $(60 \mathrm{~cm} \times 60 \mathrm{~cm}$, with 16 squares marked out on the floor) with rats unfamiliar with this environment. Social interaction was evaluated under the lighting conditions previously used (Overstreet et al, 2002). Behavioral assessment of social interaction was made after the multiple-withdrawal protocol, or after withdrawal from 5 days on ethanol diet with or without prior exposure to stress. Assessments were made by experienced observers who were blind to the treatment conditions. For this testing, two animals were placed in an arena and the amount of time animals actively interacted (ie grooming, sniffing, boxing, or crawling over/under each other) during a 5-min session was measured to assess social interaction. Behavioral assessment of social interaction was conducted between 5 and $6 \mathrm{~h}$ after the removal of the ethanol, a time when anxiety-like behavior is apparent (eg Knapp et al, 2001; Moy et al, 1997, 2000; Overstreet et al, 2002). Each squad of 40 rats was tested in subgroups of 20 , with balanced numbers of rats in each treatment group. Rat pairs were matched on the basis of alcohol intakes, body weights, and treatment conditions, and placed simultaneously in the open field (Overstreet et al, 2002).

Social interaction was determined for the multiple withdrawals and the initial studies on repeated stresses, utilizing data obtained from a rat pair as a single determination (File, 1980), or from data obtained from individual rats in the pair. The latter approach of evaluating individual rats in the pair is a modification of the standard social interaction test (File, 1980), an approach to reduce the number of animals needed for experiments. Statistical analyses of data from single animals in the pair in this and in another data set (Overstreet et al, 2003) revealed that the measures in individual rats provide the same statistical outcome as treating the social interaction scores of the rat pair as a unit. Therefore, the remaining evaluations of stress on social interaction were made on data from single animals in the pair.

While measuring social interaction, there was simultaneous recording of line crosses (by two forepaws), which served as a measure of locomotor activity. This locomotor activity determination provided an independent measure from that of social interaction (File, 1980). In a previous study of 25 pairs of rats maintained on CD and 25 on ethanol diet, the social interaction and locomotor activity were essentially independent behaviors, as there was no significant correlation between these measures in either group (Overstreet et al, 2002).

Withdrawal from Reinstatement to Chronic Ethanol as a Measurement of Recovery from the WithdrawalInduced Adaptation Responsible for the Reduction in Social Interaction Following Repeated Stresses

This experimental series determined how long the reduction in social interaction by withdrawal from the 5 days of chronic ethanol persisted in the animals that received the previous stress applications. For this determination, stressexposed rats were withdrawn from their 5-day ethanol session for $5 \mathrm{~h}$, prior to being placed in the open field for the social interaction test. The next component was to determine if the adaptive change(s) responsible for the withdrawal-induced decrease in social interaction underlying the stress application endured for an extended period. As previously described for defining the persistence of multiple-withdrawal influence on social interaction (Overstreet et al, 2002), this experiment involved re-exposing rats that underwent the stress/chronic ethanol exposure to an additional 5 days of the ethanol diet at 8 and 16 days after the final previous withdrawal. The social interaction test was carried out between 5 and $6 \mathrm{~h}$ after withdrawal from the additional 5 days of re-exposure to ethanol diet (4.5\%). The withdrawal from a single exposure to chronic ethanol diet had previously been demonstrated to be without effect on social interaction behaviors (Overstreet et al, 2002).

\section{Drug Treatments}

Selected drug doses previously tested and found effective against single and multiple withdrawals from chronic ethanol exposure (Knapp et al, 2001; Moy et al, 1997; Overstreet et al, 2003) were used to determine if the stress enhancement of the withdrawal-induced decrease in social interaction would be similarly affected. The drugs used were a $5-\mathrm{HT}_{1 \mathrm{~A}}$ agonist, buspirone $(0.6 \mathrm{mg} / \mathrm{kg} ; \mathrm{RBI}-\mathrm{Sigma}, \mathrm{St}$ Louis, MO), flumazenil, a benzodiazepine antagonist ( $5 \mathrm{mg} /$ $\mathrm{kg}$; a gift from Roche, Basel, Switzerland), and the CRF-1 receptor antagonist CRA-1000 (3 mg/kg; a gift from Taisho Pharmaceutical Co., Ltd, Omiya, Japan). The flumazenil and CRA-1000 were suspended in 0.5\% methylcellulose and administered intraperitoneally $30 \mathrm{~min}$ before the application of the stress. The buspirone was dissolved in saline and administered intraperitoneally $30 \mathrm{~min}$ before the stress application. Untreated animals were given either $0.5 \%$ methylcellulose or saline instead of drug. Social interaction and activity were measured 5-6h after the withdrawal from the final 5-day $4.5 \%$ ethanol diet exposure in the rats drugor saline-treated prior to each stress.

In order to test whether corticoids released by stress contributed to the sensitization of the withdrawal-induced reduction in social interaction, a group of animals received a dose of corticosterone (15 mg/kg; Sigma-RBI, St Louis, MO) suspended in $0.5 \%$ carboxymethylcellulose at 6 and 11 days, followed by 5 days of $4.5 \%$ ethanol diet and a subsequent withdrawal. The dose of corticosterone was 
selected from preliminary studies in which serum levels of corticosterone after corticoid injection were found to be comparable to or exceeded those for stress. Corticosterone levels in plasma were determined in a separate experiment from those in which behavior was assessed, because of the possibility that taking blood samples from the tail might disrupt social interaction behavior. The corticosterone levels were determined with a commercial RIA kit (ICN Pharmaceuticals, Costa Mesa, CA). Social interaction and activity were measured 5-6h after the withdrawal from the final 5-day ethanol exposure in the animals administered corticosterone instead of stress.

\section{Determination of Blood Ethanol}

Blood ethanol concentrations (BECs) for repeated withdrawals from the $4.5 \%$ ethanol diet and stress during continuous ethanol and prior to the single 5 days of ethanol diet were performed to make certain that differences in BECs between groups could not account for the behavioral data. BECs were determined in a separate experiment from the assessment of social interaction, to prevent any possibility that taking blood samples might disrupt social interaction behavior. The same procedure used previously for continuous and intermittent $7 \%$ ethanol exposure (Overstreet et al, 2002) was used to evaluate BEC changes for the various $4.5 \%$ alcohol diets. To obtain evidence of the specific BECs attained by the rats in the single- and repeated-withdrawal protocols on $4.5 \%$ ethanol diet, three additional groups of rats $(n=8)$ were utilized. One group had access to $4.5 \%$ ethanol in the diet for 15 consecutive days, another was subjected to three separate 5-day cycles of ethanol exposure, and a final group had BECs determined at the end of the 5-day exposure to $4.5 \%$ ethanol diet-groups used in the behavioral studies. Another group had stress applied at 6 and 11 days prior to exposure to the 5 days of chronic ethanol diet. Blood was taken from the tip of the rat's tail during the last hour of darkness on days $1,5,6,10$, 11 , and 15 of ethanol exposure for the repeated-withdrawal and continuously exposed rats. BEC for the 5-day ethanol diet-exposed animals were tested during the last hour of darkness on the day of withdrawal (ie $0 \mathrm{~h}$ ). The latter determination was compared to the BECs in a separate grouping of rats that received the 5-day ethanol diet that had previously been exposed to multiple stresses. Finally, on the final day of chronic exposure, blood was also taken at 2 and $4 \mathrm{~h}$ for all groups after the ethanol was removed.

The collected blood $(100 \mu \mathrm{l})$ and standards $(100 \mu \mathrm{l} ; 0-$ $300 \mathrm{mg} \%$ ) were mixed with $375 \mathrm{ml}$ of distilled water and $0.5 \mathrm{~g} \mathrm{NaCl}$ in $12 \times 75 \mathrm{~mm}^{2}$ borosilicate glass culture tubes. Blood ethanol samples were analyzed using a gas chromatographic method (Wallace and Dahl, 1966; Pohorecky and Brick, 1982; Knapp et al, 1993; Overstreet et al, 2002). For this determination, tubes were capped and heated at $55^{\circ} \mathrm{C}$ for $10 \mathrm{~min}$ in a water bath, whereupon $1.5 \mathrm{ml}$ of headspace gas was removed with a standard plastic $3 \mathrm{~cm}^{3}$ syringe and injected directly into an SRI $8610 \mathrm{C}$ gas chromatograph (Torrance, CA) equipped with an external syringe adapter and $1 \mathrm{~cm}^{3}$ external loading loop. The oven temperature was isothermal at $140^{\circ} \mathrm{C}$, and contained a Hayesep D column and a flame ionization detector. Hydrogen gas, carrier gas (also hydrogen), and internal air generator flow rates were
$13.3,25$, and $250 \mathrm{ml} / \mathrm{min}$, respectively. Peak retention time was $2 \mathrm{~min}$, and the areas under the curve were analyzed with SRI PeakSimple software for Windows running on a Dell Inspiron 3500 laptop computer.

\section{Data Analysis}

Statistical analyses were carried out using the GBStat software package. The data were initially analyzed by ANOVAs, with one-, two-, or three-way ANOVAs carried out depending upon the research design. If the main and/or interaction effects were statistically significant, post hoc analyses were performed using Tukey's protected $t$-tests. Owing to previous concern about the most appropriate method for analysis of social interaction (see Overstreet et al, 2003), analysis was performed on data from rat pairs as well as on data from evaluation of social behavior on individual rats in the pair for the initial results on repeated withdrawals and stresses to demonstrate equivalent results (ie see Table 1). As noted, the remaining analysis of results on social interaction is based on individual rats in the each pair.

\section{RESULTS}

\section{Effect of Repeated Stresses on Withdrawal-Induced Reduction in Social Interaction: Comparison to Withdrawal from Continuous and Multiple Ethanol Exposures}

When restraint stress was applied for $1 \mathrm{~h}$ to animals on control-liquid diet at 6 and 11 days prior to a single exposure to 5 days of $4.5 \%$ ethanol-liquid diet (Figure 1a), the reduction in social interaction (2STR-ETOH-Cy1) was comparable to that seen for rats exposed to the multiplewithdrawal paradigm (ie compare the stressed group in Figure 1a (2STR-ETOH-Cy1) with response in Figure 1b for multiple withdrawals (ETOH-Cy3)). Rats that received only a single withdrawal from 5 days of chronic ethanol diet (4.5\%) (ETOH-Cy1) exhibit no reduction in social interaction compared to the group that received control-liquid diet

Table I Comparison of Social Interaction Evaluated With Data Obtained With Pairs vs Individual Rats For Repeatedly Stressed and Multiple Withdrawn Rats

\begin{tabular}{lcc}
\hline Groups $^{\mathbf{a}}$ & $\begin{array}{c}\text { Individual rat analysis } \\
\text { (seconds-social } \\
\text { interaction) }\end{array}$ & $\begin{array}{c}\text { Pair rat analysis } \\
\text { (seconds-social } \\
\text { interaction) }\end{array}$ \\
\hline CD group $(N=16 / 8)$ & $33.3 \pm 2.0$ & $67.8 \pm 3.5$ \\
STR-ETOH-CY| $(N=12 / 6)$ & $10.7 \pm 2.7 * *$ & $23.0 \pm 5.7 * *$ \\
ETOH-CONT-STR $(N=16 / 8)$ & $\mid 4.7 \pm 2.3^{* * *}$ & $31.9 \pm 4.3 * *$ \\
CD-3-STR $(N=8 / 4)$ & $34.0 \pm 2.8$ & $68.0 \pm 6.2$ \\
& $\mathrm{~F}(4,47)=24.33^{*} * * *$ & $\mathrm{~F}(4,21)=24.32 * * *$ \\
\hline
\end{tabular}

${ }^{a}$ The $N$ values under groups indicate the number of individual animals vs the number of pairs in each group. $* * P<0.01$ compared to the $C D$ group; Tukey's test. $* * * * P<0.00$ I: The analyses for the two methods for evaluating social interaction indicate that they provide identical results. Not only are the F-values nearly identical, but also the Tukey's tests show the same significant pattern for the various groups. 


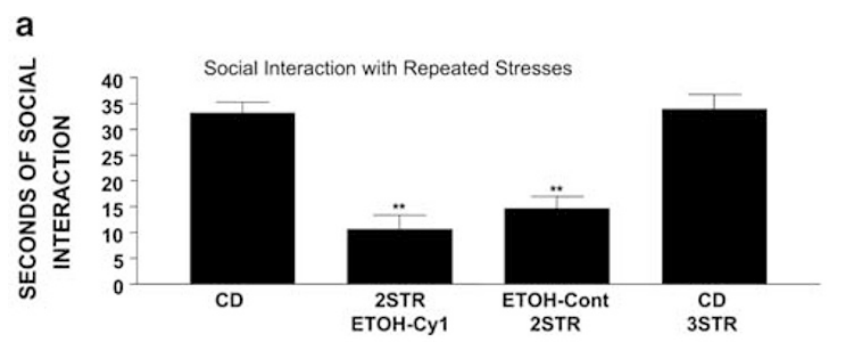

b

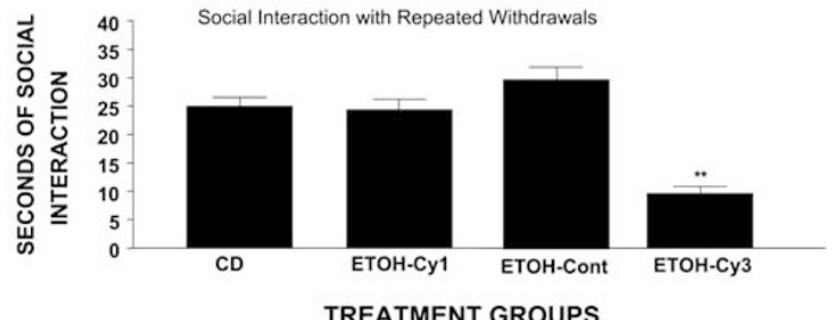

Figure I Sensitization of the withdrawal-induced reduction in social interaction by multiple stresses: comparison with multiple withdrawals. (a) Social interaction following repeated stresses: Male rats were exposed to either continuous CD or to stress applied at 6 and II days while on CD, followed by a 5 -day cycle of $4.5 \%$ ethanol liquid diet (2STR-ETOH-Cyl) prior to withdrawal. The social interaction testing was performed between 5 and $6 \mathrm{~h}$ after the final ethanol diet treatment was terminated, or 5 days after the second stress. 2STR-ETOH-Cyl = two stresses + ethanol + withdrawal. $C D=$ control diet. $C D-3 S T R=$ stressed at 6,11 , and 16 days. $\mathrm{ETOH}-\mathrm{CONT}-2 \mathrm{STR}=$ stress at 6 and II days during continuous ethanol diet + withdrawal. BECs are presented in Figure 3. The social interaction is expressed from data from individual rats in the pairs; however, in Table I, these results with individual animal values are compared with the determination obtained with pairs of rats. Social interaction was measured 5-6h after withdrawal from ethanol diet. $* * P<0.01$ compared to $C D$ or CD-3STR. (b) Social interaction after single and multiple withdrawals: Male rats were exposed to $C D, 5$ days of $4.5 \%$ ethanol diet for only I cycle (ETOH-CyI), I 5 consecutive days of $4.5 \%$ ethanol diet (ETOH-CONT), or three cycles of 5 days of $4.5 \%$ ethanol diet with 2 days interruption of diet after withdrawal from the first two cycles (ETOH-Cy3). Social interaction was measured 5-6h after the final withdrawal from ethanol diet. The social interaction is expressed from data presented as rat pairs; however, data based upon presentation of determinations of social interaction on individual rats are provided in Table I. BECs are presented in Figure 3. ** $P<0.01$ when compared to any of the other groups.

(Figure $1 \mathrm{~b}$ ). The reduction in social interaction by repeated stresses or multiple withdrawals was observed, irrespective of whether the assessment was from results obtained on pairs of rats or from findings from the individual rats in each pair (Table 1). Additionally, stress applied at 6 and 11 days when the rats were exposed to the continuous ethanol diet (ie no withdrawals) also produced a significant reduction in social interaction upon ethanol withdrawal (ETOH-CONT-2STR; Figure 1a). Rats that received only continuous $4.5 \%$ alcohol diet for 15 days (ETOH-CONT) exhibited social interaction upon withdrawal like that seen in the rats exposed to CD (Figure $1 \mathrm{~b}$ ). Social interaction $5 \mathrm{~h}$ after being exposed to three stresses (CD-3STR) was comparable to that observed with $\mathrm{CD}$ without stress (Figure 1a). Likewise, the social interaction seen with two stresses followed by 5 days on control-liquid diet ( core $=32.1 \pm 2.6 \mathrm{~s})$ was not different from that seen with CD.

Repeated stresses plus withdrawal from the single chronic ethanol exposure significantly reduced the activity, while
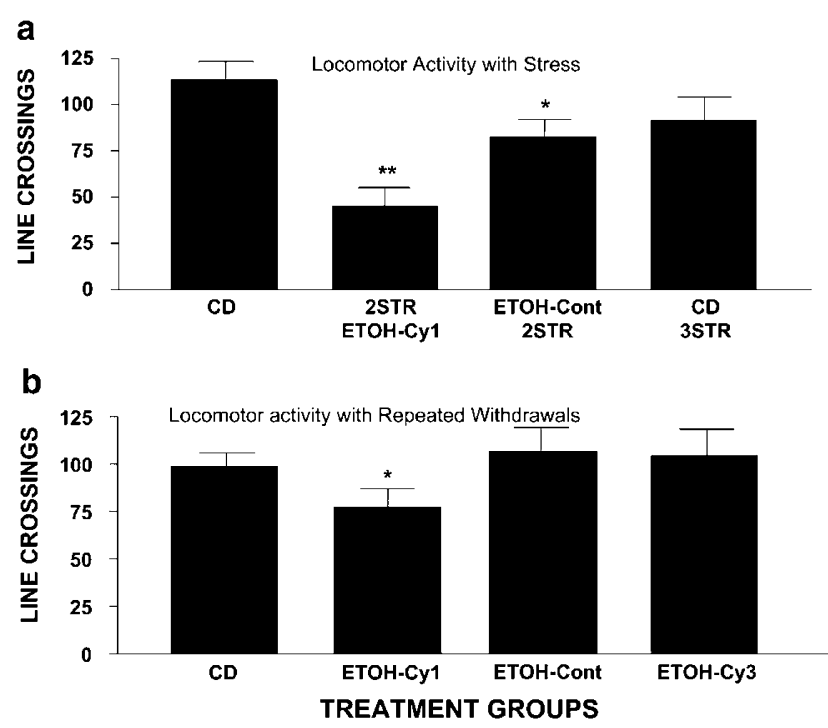

Figure 2 (a) Locomotor activity during withdrawal in the presence of stress: Experimental groups are the same as those in Figure Ia. $* P<0.05$; *** $P<0.01$ compared to CD. CD-3STR is not significantly different from CD $(P>0.05)$. (b) Locomotor activity in rats undergoing repeated withdrawals in the absence of stress. Experimental groups are the same as those in Figure Ib. $* P<0.05$ compared to the activity for any of the other groups.

the stresses alone did not (Figure 2a). In agreement with an earlier report by Overstreet et al (2002), activity was not diminished in the group that received $4.5 \%$ ethanol diet continuously (ETOH-Cont), or by the group exposed to the multiple withdrawals (ETOH-Cy3) from the ethanol diet, whereas a small reduction in activity was observed in the rats that underwent a single withdrawal from a 5-day ethanol diet exposure ethanol (ETOH-Cyl; see Figure 2b).

\section{Effect of Multiple Stresses and Withdrawals on BEC}

BECs for rats exposed to the various $4.5 \%$ ethanol diets with and without stress are illustrated in Figure 3. In each case during the course of the chronic treatments, the determination of BEC was made $1 \mathrm{~h}$ before the end of the dark cycle, as previously described (Overstreet et al, 2002). No significant differences in BEC levels were observed at the various times among the rats that received ethanol continuously, those that received the ethanol in the cycling protocol, or in the groups that were stressed (Figure 3 ). This finding is consistent with the daily alcohol intake not being different among the groups (data not shown). After withdrawal, BECs fell equally at 2 and $4 \mathrm{~h}$ in the various groups with no measurable BEC level seen at 5-6h in any of the groups, the time social interaction was determined, as shown in Figure 1. The body weights of these various groups did not differ (data not shown).

\section{Duration of the Stress-Induced Withdrawal Reduction in Social Interaction Measured by Withdrawal from Reinstatement to an Additional Chronic Ethanol Exposure}

Stressed rats tested $24 \mathrm{~h}$ after withdrawal from a 5-day ethanol exposure spent significantly less time in social 


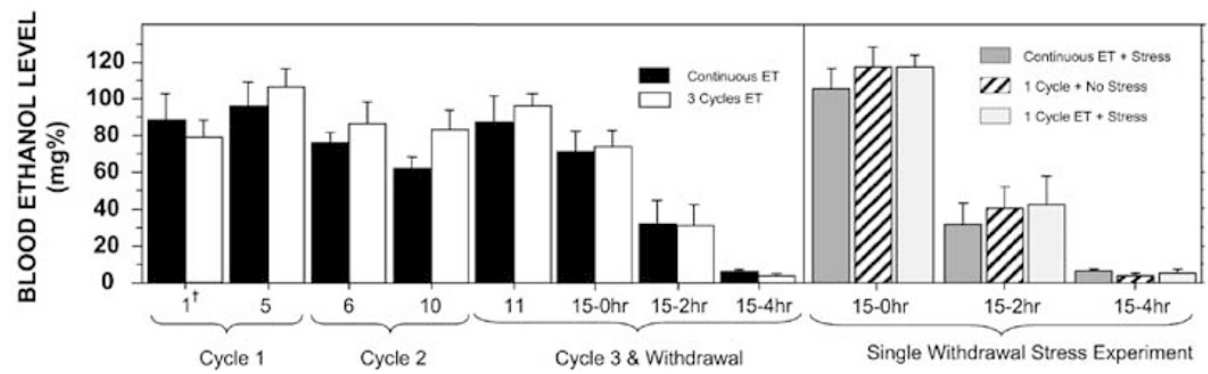

Figure 3 BECs in male rats undergoing repeated chronic ethanol exposures and repeated stresses. Rats were exposed continuously to diet for I 5 days, or received the diet in three cycles where ethanol was provided in three 5-day exposures to the 4.5\% diet with 2-day periods of CD between the fifth and sixth days and the I0th and II th days of the protocol. Blood was withdrawn from the tail tip during the last hour of darkness on days I and 5, on days 6 and I0, day II, and on day I 5 prior to withdrawal. On day I5, BECs were determined at 0, 2, and $4 \mathrm{~h}$ after the removal of the ethanol diet from the two groups of the protocol. An ANOVA revealed no significant differences among the sampling times, except for the expected reduction at 2 and $4 \mathrm{~h}$ after withdrawal from the chronic ethanol exposures. The ethanol intake of these groups of animals was not significantly different. On the right side of the figure (singlewithdrawal stress experiment), rats were administered ethanol either continuously for 15 days or in a single 5 -day cycle with I h of stress given at days 6 and II with continuous ethanol group or at days 6 and II when on CD followed by a single 5-day cycle of ethanol diet. Blood sampling during withdrawal then proceeded as above. †Treatment day (hour of withdrawal).

Table 2 Reduction in Social Interaction in Stressed/Withdrawn Rats When Withdrawn from Reinstatement to Alcohol After 8 or 16 Days on Control Diet ${ }^{\mathrm{a}}$

\begin{tabular}{|c|c|c|c|}
\hline \multirow[b]{2}{*}{ Parameters } & \multicolumn{3}{|c|}{ Treatment groups } \\
\hline & Control diet & 8-Day reinstatement & 16-Day reinstatement \\
\hline Social interaction (s) & $26.2 \pm 3.5$ & $12.0 \pm 2.8^{* * * * * *}$ & $8.5 \pm 2.4 * * * * *$ \\
\hline Alcohol intake (g/kg/day) & $\mathrm{N} / \mathrm{A}$ & $8.7 \pm 0.0$ & $7.8 \pm 0.3$ \\
\hline Body weight (g) & $318 \pm 3$ & $332 \pm 9$ & $385 \pm 8$ \\
\hline
\end{tabular}

interaction compared to $\mathrm{CD}$ rats $(\mathrm{CD}=29.4 \pm 4.1$ vs ethanol diet $=14.1 \pm 4.2 ; P<0.05)$. However, indicative of recovery, the measure of anxiety-like behavior $24 \mathrm{~h}$ later was significantly improved compared to the rats withdrawn 5$6 \mathrm{~h}$ after the final withdrawal from exposure to 5 days of chronic ethanol $(P<0.01$, Tukey's tests; data not shown).

Since reinstatement of animals that had previously been exposed to a multiple-withdrawal protocol of $7 \%$ ethanol diet resulted in an increase in anxiety-like behavior for a persistent period (Overstreet et al, 2002), it was next determined whether withdrawal from re-exposure to a single 5 days of $4.5 \%$ diet after the repeated stress and withdrawal would have a similar persistent consequence (Table 2). In this respect, when the rats that underwent the previous stresses prior to the initial withdrawal were reexposed to 5 days of $4.5 \%$ chronic ethanol diet 8 or 16 days later, a significant reduction in social interaction behavior was observed (Table 2). Since a single withdrawal from 5 days of chronic ethanol exposure does not result in a change in social interaction (see Figure 1), this finding with withdrawal from re-exposure to this single exposure to chronic ethanol indicates that the initial multiple-stress/withdrawal exposure results in a persistent adaptive change.

\section{Effect of Multiple Corticosterone Challenges on the Withdrawal-Induced Reduction in Social Interaction}

Since stress increases corticosterone, it was considered that the increase in corticosterone could be responsible for stress sensitizing the withdrawal-induced increase in anxiety-like behavior. As shown in Table 3, restraint stress increased blood corticoid levels as expected. Likewise, administration of $15 \mathrm{mg} / \mathrm{kg}$ of corticosterone raised the blood levels of this steroid to as much as or to a greater extent than that for stress itself (Table 3 ).

Subsequently, it was determined if repeated systemic administrations of $15 \mathrm{mg} / \mathrm{kg}$ of corticosterone to rats on control-liquid diet prior to a single 5-day exposure to the $4.5 \%$ ethanol diet would substitute for the two-stress sensitization of the withdrawal-induced reduction in social interaction. As shown in Figure 4a, repeated stresses, as expected, sensitized the withdrawal-induced reduction in social interaction (2STR-ETOH-Cy1). However, the animals treated at 6 and 11 days with $15 \mathrm{mg} / \mathrm{kg}$ of corticosterone did not exhibit a significant change in withdrawal-induced anxiety-like behavior (Figure 4; CORT-ETOH-Cy1). The vehicle for corticosterone was without effect on social 
Table 3 Corticosterone Levels ( $\mathrm{ng} / \mathrm{ml}$ ) Following Restraint Stress or Corticosterone Injection to Rats ${ }^{\mathrm{a}}$

\begin{tabular}{lccc}
\hline Control groups & \multicolumn{3}{c}{ Experimental groups } \\
Unhandled control & \multicolumn{3}{c}{ Restraint stress determination } \\
\cline { 2 - 4 } $\begin{array}{l}\text { Baseline value } \\
182 \pm 73\end{array}$ & $0.5 \mathrm{~h}$ & $2 \mathrm{~h}$ & $4 \mathrm{~h}$ \\
Injected control & $421 \pm 25^{*}$ & $425 \pm 80 *$ & $156 \pm 31$ \\
Baseline value & Corticosterone injection determination \\
\cline { 2 - 4 } $370 \pm 32^{\mathrm{b}}$ & $0.5 \mathrm{~h}$ & $2 \mathrm{~h}$ & $4 \mathrm{~h}$ \\
\hline
\end{tabular}

${ }^{a}$ Tail blood samples were taken from independent groups at the times indicated after initiation of restraint stress or injection of $15 \mathrm{mg} / \mathrm{kg}$ corticosterone IP. All values are expressed as $\mathrm{ng} / \mathrm{ml}$ of corticosterone. ${ }^{b}$ Baseline corticosterone was significantly elevated $(P<0.05)$ in the vehicle-injected control group and corticosterone level was significantly greater at $0.5 \mathrm{~h}$ after corticosterone injection than in the stressed group. $* P<0.05$ vs respective control each group at the designated time.
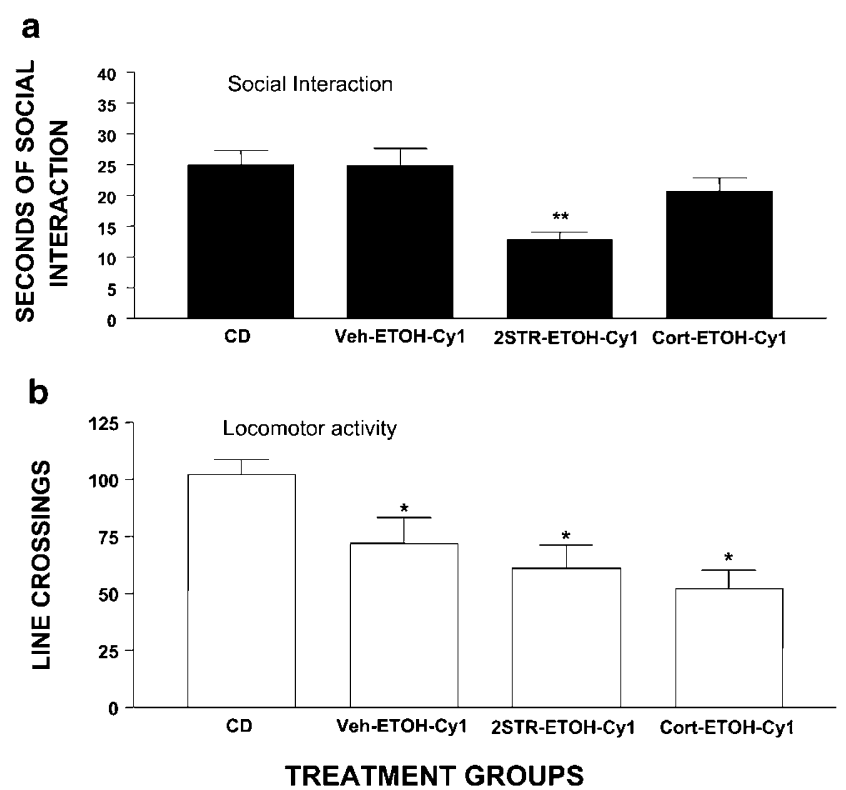

Figure 4 Effect of multiple corticosterone treatments instead of stresses on the withdrawal-induced deficit in social interaction. (a) Social interaction: In two of the groups, animals received either two stresses (2STR-ETOH$\mathrm{Cyl}$ ) or two injections of $15 \mathrm{mg} / \mathrm{kg}$ of corticosterone (CORT-ETOH-Cyl) at 6 and II days prior to withdrawal from 5 days of $4.5 \%$ ethanol diet. See corticosterone levels after these treatments are shown in Table 2. Social interaction was determined 5-6h following withdrawal from the chronic ethanol diet. Since the CD group did not differ from a group that received vehicle (Veh-ETOH-CyI) $(P>0 . I)$, these data were combined. $* * P<0.0$ I compared to Veh-ETOH-Cyl and CD groups. The 2STR-ETOH-Cyl group is not significantly different from Veh-ETOH-Cyl or CD groups $(P>0.05)$. (b) Locomotor activity: The groups are the same as those in (a) above. $* P<0.05$ compared to $C D$.

interaction seen with the single withdrawal (see VEHETOH-Cyl in Figure 4a).

As noted earlier, multiple stresses prior to chronic ethanol exposure (2STR-ETOH-Cy1) reduced activity during withdrawal compared to CD (Figure $4 \mathrm{~b}$ ). Additionally,
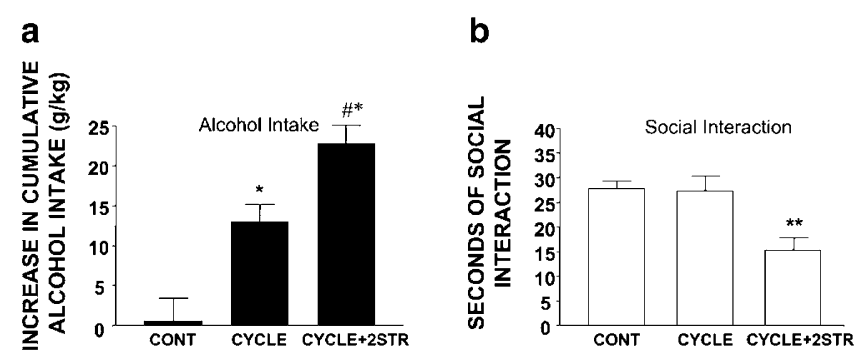

Figure 5 Effect of stress during withdrawal in the multiple-withdrawal protocol on voluntary drinking in P-rats: Relation to withdrawal-induced anxiety-like behavior. (a) Alcohol intake: P-rats were given either continuous voluntary access to water and an ethanol solution (I0\%) to drink (CONT) or three cycles of voluntary access to water and ethanol solution exposure with 2 days of abstinence between the initial two cycles (CYCLE). As noted in Methods, the baseline intake for the first 5 days is subtracted from the intake for the third 5-day exposure to voluntary ethanol. A final set of animals undergoing multiple cycles of exposure was stressed during the initial two periods of withdrawal $(4 \mathrm{~h})$ from 5 days of ethanol drinking (CYCLE + 2STR). *P $<0.05$ compared to CONT for the final 5 days of exposure. ${ }^{\#} P<0.05$ compared to $C Y C L E$ for the final 5 days of voluntary ethanol exposure. (b) Social interaction: Following the treatments outlined in Figure 5a, social interaction was assessed in each of the groups following final withdrawal from the voluntary drinking of the P-rats. When social interaction was measured 5-6h after removal of the ethanol, only the P-rats that received the multiple stresses during the first two withdrawals had a significant reduction in social interaction upon removal from the final exposure to ethanol compared to CONT and CYCLE groups $(* * P<0.01)$

reduced activity was seen during withdrawal from a single 5 -day ethanol exposure in the groups without Veh-ETOH$\mathrm{Cyl}$ or with corticosterone treatment (Cort-ETOH-Cyl; Figure $4 b)$.

\section{Stress Facilitation of Multiple-Withdrawal-Induced Drinking in P-Rats: Relation to a Withdrawal-Induced Decrease in Social Interaction}

In this experimental series, stress was applied to ethanolpreferring P-rats during withdrawal from the first and second cycles of voluntary ethanol drinking of a $10 \%$ ethanol solution in the multiple-withdrawal protocol. The purpose was to determine whether combining these treatments would affect voluntary ethanol intake in this ethanol-preferring strain.

When the baseline drinking for the first 5 days was subtracted from the cumulative intake on the third 5-day cycle of ethanol drinking (see Methods), there was a significant increase in voluntary drinking in the P-rats that underwent only multiple withdrawals (deprivations; CYCLE; Figure 5a; see Sinclair, 1972) compared to the rats with ethanol continuously available (CONT; Figure 5a). There was an even greater increase in voluntary drinking over the 5 days upon the third exposure to ethanol in the group stressed during the previous two withdrawals (CYCLE + STR) when compared to the rats on continuous ethanol exposure (CONT) or the rats that underwent multiple withdrawals but were not stressed (CYCLE; see Figure 5a). All groups in Figure 5a exposed to ethanol after withdrawal had elevated ethanol drinking on the first day of the final cycle of renewed drinking. While the level of 
ethanol drinking in the $\mathrm{P}$-group repeatedly exposed to ethanol without stress (CYCLE group) returned to baseline by the end of the 5-day ethanol exposure, the level of ethanol drinking in the stressed group (CYCLE + STR) remained significantly elevated over the remaining 4 days $(P<0.05$; data not shown), accounting for the greater increase in voluntary drinking in the CYCLE + STR group compared to the CYCLE group over the 5-day total (Figure 5a).

With respect to anxiety-like behavior during the final withdrawal from voluntary drinking in the multiple-withdrawal protocol in the animals stressed between the first and second withdrawals (CYCLE + STR), a significant reduction in social interaction was observed (Figure 5b). The other groups of animals that underwent only repeated withdrawals or had ethanol continuously (CONT) available exhibited no change in social interaction response during withdrawal from voluntary drinking (Figure 5b). This latter observation (Figure 5b) indicates that the excess drinking induced by stress in P-rats during withdrawal from voluntary drinking in the multiple-withdrawal protocol was sufficient to induce an adaptive change that resulted in a withdrawal-induced reduction in social interaction not seen in other groups.

\section{Effect of Selected Drugs Prior to Repeated Restraint Stresses on Sensitization of Social Interaction Reduction During a Single Withdrawal}

Previous investigations showed that specific drug treatments, including CRF-1 and benzodiazepine receptor antagonists and a 5- $\mathrm{HT}_{1 \mathrm{~A}}$ agonist, given prior to the initial two withdrawals of the multiple-withdrawal protocol, blocked the sensitization of anxiety-like behavior (see Knapp et al, 2001; Overstreet et al, 2002, 2003). Therefore, in this investigation, these drugs were given prior to the initial two stresses, but not the withdrawal from the single chronic ethanol exposure. The purpose was to determine if these drug treatments would block the stress-induced sensitization of the decrease in social interaction, just as they blocked the sensitization induced by multiple withdrawals.

As noted above (Figures 3 and 4), stress significantly reduced social interaction in the animals that received vehicle (2STR-ETOH-VEH; Figure 6a). In Figure 6a, pretreatment with $3 \mathrm{mg} / \mathrm{kg}$ of the CRF-1 receptor antagonist CRA-1000 (2STR-ETOH-CRA), $5 \mathrm{mg} / \mathrm{kg}$ of the benzodiazepine receptor antagonist, flumazenil (2STR-ETOH-FLU), or $0.6 \mathrm{mg} / \mathrm{kg}$ of the $5-\mathrm{HT}_{\mathrm{IA}}$-receptor agonist buspirone (2STRETOH-BUS) prior to the stress is shown to minimize the withdrawal-induced reduction in social interaction associated with application of the repeated stresses (Figure 6a). Comparable effects of these drugs were seen on the withdrawal-induced anxiety-like behavior in the repeatedwithdrawal protocol (Knapp et al, 2001; Overstreet et al, 2003). When drugs were given alone while rats received only $\mathrm{CD}$, these treatments had no effect on social interaction following withdrawal from a later single exposure to $4.5 \%$ ethanol diet (Overstreet et al, 2003; unpublished data).

As before, activity was reduced during withdrawal in the group that received repeated stresses prior to withdrawal (Figure $6 \mathrm{~b}$ ). This activity reduction was minimized in the
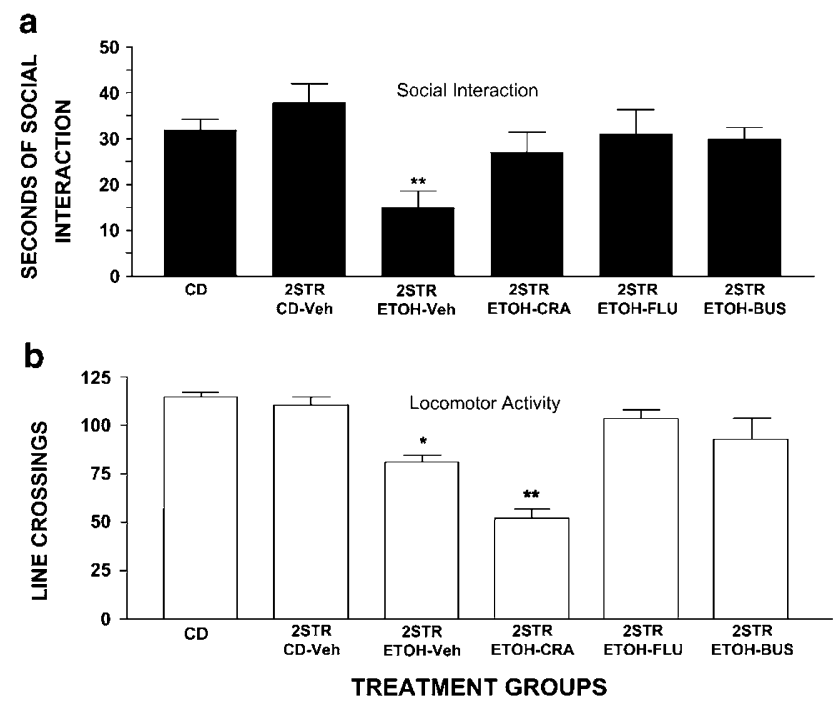

Figure 6 Effect of selected receptor agents on the stress sensitization of the withdrawal deficit in social interaction. (a) Social interaction: $\mathrm{CD}=$ control-liquid diet. 2STR-ETOH-Veh = two cycles of restraint stress $(\mathrm{I})$ at 6 and II days while on liquid diet, followed by withdrawal from $4.5 \%$ ethanol diet. 2STR-CD-VEH $=$ vehicle at 6 and II days prior to stress administered when rats on CD (ie no ethanol). 2STR-ETOH-Veh = rats received two stresses with pretreatment with vehicle for drugs plus chronic ethanol diet followed by withdrawal. All other groups received a selected drug prior to each of the restraint stresses. 2STR-ETOH-CRA = rats received $3 \mathrm{mg} / \mathrm{kg}$ of the CRF-I receptor antagonist CRA-I000 prior to stress. $2 \mathrm{STR}$-ETOH-FLU = rats received $5 \mathrm{mg} / \mathrm{kg}$ of flumazenil, a benzodiazepine receptor antagonist, prior to stress. 2STR-ETOH-BUS = rats received $0.6 \mathrm{mg} / \mathrm{kg}$ of the $5-\mathrm{HT} / \mathrm{A}$-receptor agonist buspirone prior to stress. The social interaction testing was performed between 5 and $6 \mathrm{~h}$ after the final ethanol diet treatment was terminated. When drugs were administered in the absence of stress while rats drank liquid diet, there was no influence on social interaction behavior with withdrawal from the chronic ethanol exposure (Overstreet et al, 2003; unpublished data). ** $P<0.0$ I compared to CD or 2-STR-CD-Veh. 2STR-ETOH-CRA, 2STRETOH-FLU, and 2STR-ETOH-BUS do not differ from CD or 2STR-CDVeh $(P>0.1)$. (b) Locomotor activity: $* P<0.05$; $* * P<0.0$ I compared to 2STR-ETOH-VEH or CD groups. Pretreatment with flumazenil (2STRETOH-FLU) and buspirone (2STR-ETOH-BUS) blocked the reduced activity induced by 2-STR-ETOH-Veh $(P<0.05)$, whereas pretreatment with CRA-I000 (2STR-ETOH-CRA) enhanced the reduction seen with 2STR-ETOH-Veh $(P<0.05)$

groups that received flumazenil (2STR-ETOH-FLU) and buspirone (2STR-ETOH-BUS), but was accentuated during withdrawal in the group pretreated with the CRF-1 receptor antagonist (2STR-ETOH-CRA) prior to stress (Figure 6b).

\section{DISCUSSION}

The present investigation confirms an earlier report that multiple withdrawals from brief chronic ethanol exposures sensitize animals to anxiety-like behavior (Knapp et al, 2001; Overstreet et al, 2002, 2003), and is consistent with repeated deprivation episodes increasing withdrawal-induced anxiety (Hölter et al, 1998). Thus, these findings support an earlier speculation that multiple withdrawals during chronic alcoholism can result in an enhancement of symptoms of withdrawal other than seizures (Ballenger and Post, 1978; Malcolm et al, 2000a). 
An important new finding in the present investigation was that repeated restraint stresses in the absence of alcohol diet decreased social interaction upon withdrawal from exposure to a single 5 days of $4.5 \%$ ethanol diet. Similarly, stress applied when the rats received the chronic ethanol diet continuously also led to a significant withdrawalinduced reduction in social interaction. The withdrawal from neither a single cycle nor continuous ethanol diet exposure alone altered social interaction, an additional confirmation of earlier work (Overstreet et al, 2002). Accompanying this evaluation of repeated stresses on withdrawal-induced anxiety-like behavior was an investigation to determine if two or three stresses in the absence of any alcohol exposure would affect social interaction tested 5-6 $\mathrm{h}$ after the last stress, the same time at which testing occurred after withdrawal from chronic ethanol exposure. In the absence of chronic ethanol, the stresses alone did not emulate the behavioral change associated with withdrawal from chronic ethanol. These experimental findings provide the first evidence that a synergistic interaction between previous stresses and chronic ethanol exposure sensitizes withdrawal-induced anxiety-like behavior.

The lack of differing BECs among the groups is consistent with the amount of ethanol diet ingested or its metabolism not being affected by the repeated withdrawals or the repeated stresses. Consequently, a change in BECs cannot explain the sensitization of the withdrawal reduction in social interaction associated with the repeatedly stressed or multiple-withdrawn animals. Additionally, the BECs that accompanied the $4.5 \%$ ethanol diet were low, only at a level of legal intoxication (Figure 3 ). Thus, this latter observation of low BECs associated with the sensitization of anxiety-like behavior following repeated withdrawal- or stress-induced reduction in social interaction following withdrawal suggests that the adaptive change responsible for this behavioral change could be initiated at levels of ethanol observed in problem drinkers who have undergone only a limited number of cycles of stress and ethanol intake.

Previous work demonstrated a significant persistent effect of repeated withdrawals from $7 \%$ ethanol diet on anxietylike behavior for up to 32 days upon withdrawal from reexposure to 5 days of chronic ethanol exposure (Overstreet et al, 2002). In the present investigation, animals exposed to repeated stresses prior to a single 5 days of $4.5 \%$ ethanol diet showed a significant decrease in social interaction upon subsequent withdrawal from re-exposure to this chronic ethanol diet regimen 16 days later, indicative of a persistent adaptive change. Consequently, in addition to the previously reported persistent change in sensitivity to the withdrawal reduction in social interaction after multiple withdrawals (Overstreet et al, 2002), stress when combined with withdrawal from a single exposure to chronic ethanol can also induce a persistent enhancement of withdrawalinduced anxiety-like behavior.

Since chronic ethanol and withdrawal (see Rivier et al, 1984; Spencer and McEwen, 1990; Rasmussen et al, 2000; Zorrilla et al, 2001) as well as stress (Table 2; see Kim et al, 2000; Garcia and Armario, 2001) can increase corticoids in plasma, it was reasonable to consider that cyclic release of corticoids during the multiple stresses could be activating neural pathways involved in the sensitization of the withdrawal-induced reduction in social interaction. To test this view, animals on control-liquid diet were exposed to corticosterone in place of the two stresses prior to withdrawal from a single 5-day exposure to chronic ethanol. The substitution of the corticoid treatment for the two stresses did not change social interaction following withdrawal from the single exposure to chronic ethanol. These latter data clearly demonstrate that the increase of corticoids during stress cannot explain the sensitization of the withdrawal-induced decrease in social interaction.

An additional experiment undertaken was to determine if stress administered during withdrawal from the repeated ethanol protocol would affect additional behavior, i.e. voluntary ethanol drinking in the P-rat. In this study, it was demonstrated that the repeated-withdrawal protocol induced greater voluntary drinking of ethanol compared to that observed with continuous ethanol exposure. This change could be considered comparable to multiple cycles of alcohol deprivation enhancing drinking in the P-rat, as previously described (Rodd-Henricks et al, 2000, 2001). A particular key observation was the further increase in drinking following restraint stress application during the initial two withdrawals of the multiple-withdrawal protocol. This degree of drinking induced by stress was sufficient to result in an increase in withdrawal-induced anxiety-like behavior upon the final withdrawal from the multiple voluntary chronic ethanol drinking episodes, a result not observed in the group that received only multiple withdrawals from voluntary ethanol drinking. This stressinduced voluntary drinking of ethanol could be considered comparable to the stress-induced increase in alcoholseeking behavior seen by others (Lê et al, 1998, 2000; Weiss, 2002; Liu and Weiss, 2002). Consequently, stressinduced sensitization of voluntary drinking in the P-rats during the multiple-withdrawal sequence would seem relevant to the production of adaptive change in alcoholics that accentuate symptoms that drive craving, relapse (ie loss of control), and continued abuse of alcohol (see Brown et al, 1995; Sinha and O’Malley, 1999; Sinha, 2001). Therefore, stress-induced drinking will need to be examined in greater detail in the future, because it may be a means to model the negative affect induced by stress during abstinence.

Previous studies demonstrated that the administration of selected drugs during the initial two withdrawals, but not the third, of the multiple-withdrawal protocol could minimize the multiple-withdrawal-induced sensitization of the decrease in social interaction (Knapp et al, 2001; Overstreet et al, 2003). These drugs included a CRF-1 receptor antagonist, flumazenil, a benzodiazepine receptor antagonist, and a $5-\mathrm{HT}_{1 \mathrm{~A}}$-receptor agonist (Knapp et al, 2001; Overstreet et al, 2003). Based upon the general observation suggesting a parallelism between the multiple withdrawals and the stress activation on the withdrawalinduced reduction in social interaction, drugs effective against the adaptive change induced by multiple withdrawals were tested on the action of stress to enhance the withdrawal-induced reduction in social interaction (unpublished data; Overstreet et al, 2003). Administration of the CRF-1 receptor antagonist CRA-1000 and the benzodiazepine receptor antagonist flumazenil, as well as treatment with the $5-\mathrm{HT}_{1 \mathrm{~A}}$-receptor agonist, buspirone, prior to each of the two applications of restraint stress blocked the stressinduced decrease in social interaction seen with withdrawal 
from the 5 days of chronic ethanol exposure. These latter findings on stress are consistent with previous work demonstrating that a CRF-1 receptor antagonist (Knapp et al, 2001), flumazenil (File et al, 1989; Moy et al, 1997; Knapp et al, 2001), and buspirone (Overstreet et al, 2003) reduced the anxiety-like behavior observed upon withdrawal from chronic ethanol exposure. Thus, from the pharmacological investigations, multiple stresses prior to exposure to withdrawal from chronic ethanol appears to involve neural mechanisms attributable to those observed with multiple withdrawals to sensitize anxiety-like behavior.

The CRF-1 receptor antagonist inhibition of stress sensitization of the withdrawal-induced reduction in social interaction implicates cyclic CRF release being responsible for the adaptive change following the repeated stresses. However, the basis of flumazenil blocking the adaptive change induced by the repeated stresses to induce a withdrawal reduction in social interaction remains problematic. It is known that a benzodiazepine agonist blocks the adaptive change induced by multiple withdrawals, whereas a benzodiazepine inverse agonist substituted for stress or the initial two withdrawals of the multiple-withdrawal protocol increases withdrawal-induced anxiety-like behavior (unpublished data). Flumazenil, as a benzodiazepine antagonist, could be blocking the action of an endogenous compound acting as a benzodiazepine inverse agonist (see Bormann, 1991; Ferrarese et al, 1993), or could be acting as a partial benzodiazepine agonist on $\mathrm{GABA}_{\mathrm{A}}$ receptors (Skerritt and MacDonald, 1983; Wafford et al, 1996; Weiss et al, 2002) to minimize the action of stress to sensitize the withdrawal-induced reduction in social interaction. Future exploration of these potential actions of flumazenil will be required to resolve the underlying means by which this drug blocks the reduction in withdrawal-induced anxiety-like behavior following repeated exposures to stress. In unpublished data, we found that the dose of a $5-\mathrm{HT}_{2 \mathrm{C}}$ receptor antagonist (SB242084), which minimized the adaptation responsible for the decrease in social interaction induced by the multiple-withdrawal protocol (Knapp et al, 2001; Overstreet et al, 2003), was without effect against the stress-induced sensitization of anxiety-like behavior following withdrawal. Given the effectiveness of the $5-\mathrm{HT}_{1 \mathrm{~A}}$ receptor agonist against the stress sensitization of the withdrawal-induced reduction in social interaction and the absence of the effect of the $5-\mathrm{HT}_{2 \mathrm{C}}$ receptor antagonist, future evaluation will be required to understand the potential mechanism of serotonergic involvement in the stress sensitization of withdrawal-induced anxiety-like behavior.

Others have demonstrated that the actions of centrally administered CRF are not blocked by hypophysectomy (Berridge and Dunn, 1989; McKay and Adamec, 1993) or by dexamethasone pretreatment (Britton et al, 1986), indicative that CRF can act independent of peripheral activation of the HPA axis. With the lack of effect of peripherally administered corticoids on the stress sensitization of withdrawal-induced anxiety-like behavior, CRF-1 receptor antagonism preventing this behavioral sensitization provides further support that the central action of CRF, not the peripheral release of corticoids, is critical to the adaptation responsible for this stress-induced reduction in social interaction associated with withdrawal from chronic ethanol exposure. This conclusion is also consistent with the results obtained by Lê et al (2000), who found that peripheral corticoids did not contribute to stress-induced relapse of alcohol-seeking behavior.

In addition to the withdrawal-induced decrease in social interaction by stress, a decrease in motor activity was observed with stress exposure prior to withdrawal from chronic ethanol intake. This consequence is much like the reduced activity observed with multiple withdrawals from a higher intake of chronic ethanol (Overstreet et al, 2002). While flumazenil and buspirone diminished the withdrawal-induced decrease in activity in the animals exposed to stress, the CRF-1 receptor antagonist (CRA1000) actually enhanced this withdrawal-induced diminished activity. Since flumazenil, the CRF-1 receptor antagonist, and the $5-\mathrm{HT}_{1 \mathrm{~A}}$-receptor agonist minimized the reduction in social interaction induced by stress, these data on activity suggest that social interaction and activity are independent measures of withdrawal. Certainly, the changed activity induced by stress during withdrawal does not explain the withdrawal increase in anxiety-like behavior. Further, because of these drug findings on the two measures, it is concluded that not all symptoms of withdrawal have the same neurochemical basis.

The tension-reduction hypothesis of alcoholism provides a view that stress contributes to alcohol abuse (see Kalodner et al, 1989; Young et al, 1990; Kushner et al, 1994). There has been a prominent resurgence of studies defining the risk of stress on drug abuse and relapse (see Sinha, 2001). The present investigation indicates that adaptive changes by stress contribute to functional changes in social interaction during ethanol withdrawal, and enhance drinking in alcohol-preferring rats when applied during a multiplewithdrawal protocol. The hypothesis that alcohol abuse is due to 'hedonic homeostatic dysfunction' (Koob and LeMoal, 1997; Koob, 2000, 2003) proposes that sensitization processes from adaptations during the course of alcohol abuse contribute to an 'allostatic' change that contributes to relapse. The present results would suggest that stress may contribute to this 'allostatic' adaptation. The integration of the adaptations induced by multiple withdrawals and the adaptations induced by stress interacting with chronic alcohol exposure to enhance withdrawal-induced anxietylike behavior as well as the alcohol-deprivation effect provides a logical basis for assuming that such interactions facilitate symptomatic characteristics of alcoholism. These characteristics include enhanced withdrawal symptoms, desire to drink during relapse, and uncontrolled drinking upon loss of sobriety. The protocols outlined in the present investigation provide a means to investigate this view of alcohol abuse further.

Future investigations will need to assess the neuroanatomical basis of the adaptation(s) associated with stress induction of anxiety-like behavior, and whether additional neurotransmitter mechanisms have a role in this interaction of multiple stresses and ethanol withdrawal to sensitize anxiety-like behavior. Additionally, it will be important to determine if the enhanced drinking observed in the P-rats stressed during the period of withdrawal in the repeatedwithdrawal paradigm is supported by the same adaptations responsible for the multiple-withdrawal-induced decrease in social interaction. Given that adaptive changes in either 
neurotransmitter release or receptor function associated with CRF-, serotonin-, and GABA-containing pathways likely contribute to the stress-induced sensitization of the withdrawal reduction in social interaction, another question to be addressed in the future is whether the drugs that inhibit the sensitization processes associated with stress can be potential treatments for selected withdrawal symptoms and craving in the alcoholic to minimize further ethanol abuse.

\section{ACKNOWLEDGEMENTS}

We wish to thank Milli Senapati for technical assistance and the Indiana Alcohol Center for providing the breeding pairs to initiate a colony of ethanol-preferring P-rats. This work was supported by grants from NIAAA: AA11605, AA00253, AA00214, AA14284, AA12655.

\section{REFERENCES}

Andrews N, File SE, Fernandes C, Gonzalez LE, Barnes NM (1997). Evidence that the median raphe nucleus-dorsal hippocampal pathway mediates diazepam withdrawal-induced anxiety. Psychopharmacology 130: 228-234.

Ballenger JC, Post RM (1978). Kindling as a model for alcohol withdrawal syndromes. Br J Psychiatry 133: 1-14.

Becker HC, Diaz-Granados JL, Weathersby RT (1997). Repeated ethanol withdrawal experience increases the severity and duration of subsequent withdrawal seizures in mice. Alcohol 14: $319-326$.

Becker HC, Hale RL (1993). Repeated episodes of ethanol withdrawal potentiate the severity of subsequent withdrawal seizures: an animal model of alcohol withdrawal 'kindling'. Alcoholism Clin Exp Res 17: 94-98.

Becker HC, Veatch LM, Diaz-Granados JL (1998). Repeated ethanol withdrawal experience selectively alters sensitivity to different chemoconvulsant drugs in mice. Psychopharmacology 139: 145-153.

Berridge CW, Dunn AJ (1989). CRF and restraint-stress decrease exploratory behavior in hypophysectomized mice. Pharmacol Biochem Behav 34: 517-519.

Bhattacharya SK, Satyan KS, Chakrabarti A (1997). Anxiogenic action of caffeine: an experimental study in rats. J Psychopharmacol 11: 219-224.

Bormann J (1991). Electrophysiological characterization of diazepam binding inhibitor (DBI) on $\mathrm{GABA}_{\mathrm{A}}$ receptors. Neuropharmacology 30: 1387-1389.

Britton DR, Varela M, Garcia A, Rosenthal M (1986). Dexamethasone suppresses pituitary-adrenal but not behavioral effects of centrally administered CRF. Life Sci 38: 211-216.

Brown ME, Anton RF, Malcolm R, Ballenger JC (1988). Alcohol detoxification and withdrawal seizures: clinical support for a kindling hypothesis. Biol Psychiatry 23: 507-514.

Brown SA, Vik PW, McQuaid JR, Patterson TL, Irwin MR, Grant I (1990). Severity of psychosocial stress and outcome of alcoholism treatment. J Abnorm Psychol 99: 344-348.

Brown SA, Vik PW, Patterson TL, Grant I, Schuckit MA (1995). Stress, vulnerability and adult alcohol relapse. J Stud Alcohol 56: 538-545.

Chaouloff F, Berton O, Mormede P (1999). Serotonin and stress. Neuropsychopharmacology 21(Suppl 2): 28S-32S.

Ferrarese C, Appollonio I, Bianchi G, Frigo M, Marzorati C, Pecora $\mathrm{N}$ et al (1993). Benzodiazepine receptors and diazepam binding inhibitor: a possible link between stress, anxiety and the immune system. Psychopharmacology 18: 3-22.
Ferrarese C, Mennini T, Pecora N, Gobbi M, Appollonio I, Bernasconi $\mathrm{P}$ et al (1991b). Acute noise stress in rats increases the levels of diazepam binding inhibitor (DBI) in hippocampus and adrenal gland. Psychopharmacology 103: 339-342.

Ferrarese C, Mennini T, Pecora N, Pierpaoli C, Frigo M, Marzorati C et al (1991a). Diazepam binding inhibitor (DBI) increases after acute stress in rat. Neuropharmacology 30: 1445-1452.

File SE (1980). The use of social interaction as a method for detecting anxiolytic activity of chlordiazepoxide-like drugs. J Neurosci Methods 2: 219-238.

File SE (1993). The social interaction test of anxiety. Neurosci Protocols 10: 1-7.

File SE, Andrews N, al-Farhan M (1993). Anxiogenic responses of rats on withdrawal from chronic ethanol treatment: effects of tianeptine. Alcohol Alcoholism 28: 281-286.

File SE, Baldwin HA, Hitchcott PK (1989). Flumazenil but not nitrendipine reverses the increased anxiety during ethanol withdrawal in the rat. Psychopharmacology 98: 262-264.

File SE, Hyde JR (1978). Can social interaction be used to measure anxiety? Br J Pharmacol 62: 19-24.

File SE, Lister RG (1984). Do the reductions in social interaction produced by picrotoxin and pentylenetetrazole indicate anxiogenic actions? Neuropharmacology 23: 793-796.

Fils-Aime ML, Eckardt MJ, George DT, Brown GL, Mefford I, Linnoila M (1996). Early-onset alcoholics have lower cerebrospinal fluid 5-HIAA levels than late onset alcoholics. Arch Gen Psychiatry 53: 211-216.

Frye GD, McCown TJ, Breese GR (1983). Differential sensitivity of ethanol withdrawal signs in the rat to $\gamma$-aminobutyric acid (GABA) mimetics: blockade of audiogenic seizures but not forelimb tremors. J Pharmacol Exp Ther 226: 720-725.

Fujino K, Yoshitake T, Inoue O, Ibii N, Kehr J, Ishida J et al (2002). Increased serotonin release in mice frontal cortex and hippocampus induced by acute physiological stressors. Neurosci Lett 320: 91-95.

Garcia A, Armario A (2001). Individual differences in the recovery of the hypothalamic-pituitary-adrenal axis after termination of exposure to a severe stressor in outbred male Sprague-Dawley rats. Psychoneuroendocrinology 26: 363-374.

Guy AP, Gardner CR (1985). Pharmacological characterisation of a modified social interaction model of anxiety in the rat. Neuropsychobiology 13: 194-200.

Heinz A, Mann K, Weinberger DR, Goldman D (2001). Serotonergic dysfunction, negative mood states, and response to alcohol. Alcoholism Clin Exp Res 25: 487-495.

Hölter SM, Engelmann M, Kirschke C, Liebsch G, Landgraf R, Spanagel R (1998). Long-term ethanol self-administration with repeated ethanol deprivation episodes changes ethanol drinking pattern and increases anxiety-related behaviour during ethanol deprivation in rats. Behav Pharmacol 9: 41-48.

Irvine EE, Bagnalasta $M$, Marcon $C$, Motta $C$, Tessari M, File SE et al (2001). Nicotine self-administration and withdrawal: modulation of anxiety in the social interaction test in rats. Psychopharmacology 153: 315-320.

Kalodner CR, Delucia JL, Ursprung AW (1989). An examination of the tension reduction hypothesis: the relationship between anxiety and alcohol in college students. Addictive Behav 14: 649-654.

Katsura M, Ohkuma S, Jun X, Tsujimura A, Kuriyama K (1995a). Ethanol stimulates diazepam binding inhibitor (DBI) mRNA expression in primary cultured neurons. Mol Brain Res 34: 355-359.

Katsura M, Ohkuma S, Tsujimura A, Kuriyama K (1995b). Increase of diazepam binding inhibitor mRNA levels in the brains of chronically ethanol-treated and -withdrawn mice. J Pharmacol Exp Ther 273: 1529-1533.

Katsura M, Ohkuma S, Tsujimura A, Xu J, Hibino Y, Ishikawa E et al (1998). Functional involvement of benzodiazepine receptors in 
ethanol-induced increases of diazepam binding inhibitor (DBI) and its mRNA in the mouse brain. Mol Brain Res 54: 124-132.

Kim DH, Jung JS, Kim HS, Suh HW, Son BK, Kim YH et al (2000). Inhibition of brain protein kinase $\mathrm{C}$ attenuates immobilization stress-induced plasma corticosterone levels in mice. Neurosci Lett 291: 69-72.

Knapp DJ, Benjamin D, Pohorecky LA (1993). Effects of gepirone on ethanol consumption, exploratory behavior, and motor performance in rats. Drug Dev Res 26: 319-341.

Knapp DJ, Overstreet DH, Breese GR (2001). Persistent effects of repeated ethanol withdrawal are blunted by pharmacological treatments during early withdrawal episodes. Alcoholism Clin Exp Res 25: 23A.

Kokka N, Sapp DW, Taylor AM, Olsen RW (1993). The kindling model of alcohol dependence: similar persistent reduction in seizure threshold to pentylenetetrazol in animals receiving chronic ethanol or chronic pentylenetetrazol. Alcoholism Clin Exp Res 17: 525-531.

Koob GF (2000). Animal models of craving for ethanol. Addiction 95(Suppl 2): S73-S81.

Koob GF (2003). Alcoholism: allostasis and beyond. Alcoholism Clin Exp Res 27: 232-243.

Koob GF, LeMoal M (1997). Drug abuse: Hedonic homeostatic dysfunction. Science 278: 52-57.

Kushner MG, Sher KJ, Wood MD, Wood PK (1994). Anxiety and drinking behavior: moderating effects of tension-reduction alcohol outcome expectancies. Alcoholism Clin Exp Res 18: 852-860.

Lê AD, Harding S, Juzytsch W, Watchus J, Shalev U, Shaham Y (2000). The role of corticotrophin-releasing factor in stressinduced relapse to alcohol-seeking behavior in rats. Psychopharmacology 150: 317-324.

Lê AD, Quan B, Juzytch W, Fletcher PJ, Joharchi N, Shaham Y (1998). Reinstatement of alcohol-seeking by priming injections of alcohol and exposure to stress in rats. Psychopharmacology 135: $169-174$

Lightowler S, Kennett GA, Williamson IJ, Blackburn TP, Tulloch IF (1994). Anxiolytic-like effect of paroxetine in the rat social interaction test. Pharmacol Biochem Behav 49: 281-285.

Liu X, Weiss F (2002). Additive effect of stress and drug cues on reinstatement of ethanol seeking: Exacerbation by history of dependence and role of concurrent activation of corticotropinreleasing factor and opioid mechanisms. J Neurosci 22: 7856-7861.

Maier DM, Pohorecky LA (1989). The effect of repeated withdrawal episodes on subsequent withdrawal severity in ethanol-treated rats. Drug Alcohol Depend 23: 103-110.

Malcolm R, Herron JE, Anton RF, Roberts J, Moore J (2000a). Recurrent detoxification may elevate alcohol craving as measured by the obsessive compulsive drinking scale. Alcohol 20: 181-185.

Malcolm R, Roberts J-S, Wang W, Myrick H, Anton RF (2000b). Multiple previous detoxifications are associated with less responsive treatment and heavier drinking during an index outpatient detoxification. Alcohol 22: 159-164.

Matuszewich L, Filon ME, Finn DA, Yamamoto BK (2002). Altered forebrain neurotransmitter responses to immobilization stress following 3,4-methylenedioxymethamphetamine. Neuroscience 110: $41-48$.

McCown TJ, Breese GR (1990). Multiple withdrawals from chronic ethanol 'kindles' inferior collicular seizure activity: evidence for kindling of seizures associated with alcoholism. Alcoholism Clin Exp Res 14: 394-399.

McKay DW, Adamec R (1993). The effects of CRF and á-helical CRF on anxiety in normal and hypophysectomized rats. Soc Neurosci Abstr 19: 373.

Meert TF, Huysmans H (1994). Repeated characterization of alcohol withdrawal reactions in rats chronically exposed to an alcohol liquid diet. Prog Neuropsychopharmacol Biol Psychiatry 18: $947-960$.

Moy SS, Knapp DJ, Criswell HE, Breese GR (1997). Flumazenil blockade of anxiety following ethanol withdrawal in rats. Psychopharmacology 131: 354-360.

Moy SS, Knapp DJ, Duncan GE, Breese GR (2000). Enhanced ultrasonic vocalization and Fos protein expression following ethanol withdrawal: effects of flumazenil. Psychopharmacology 152: 208-215.

Ohkuma S, Katsura M, Tsujimura A (2001). Alterations in cerebral diazepam binding inhibitor expression in drug dependence: a possible biochemical alteration common to drug dependence. Life Sci 68: 1215-1222.

Overstreet DH, Knapp DJ, Breese GR (2002). Accentuated decrease in social interaction in rats subjected to repeated ethanol withdrawals. Alcoholism Clin Exp Res 26: 1259-1268.

Overstreet DH, Knapp DJ, Moy SS, Breese GR (2003). Prevention of the accentuated anxiety associated with repeated withdrawals from chronicethanol exposure by a $5-\mathrm{HT}_{2 \mathrm{C}}$ antagonist and a 5$\mathrm{HT}_{1 \mathrm{~A}}$ agonist. Psychopharmacology 167: 344-352.

Pohorecky LA (1991). Stress and alcohol interaction: an update of human research. Alcoholism Clin Exp Res 15: 438-459.

Pohorecky LA, Brick J (1982). A new method for the determination of blood ethanol levels in rodents. Pharmacol Biochem Behav 16: 693-696.

Rasmussen DD, Boldt BM, Bryant CA, Mitton DR, Larsen SA, Wilkinson CW (2000). Chronic daily ethanol and withdrawal: 1 . Long-term changes in the hypothalamo-pituitary-adrenal axis. Alcoholism Clin Exp Res 24: 1836-1849.

Rassnick S, Heinrichs SC, Britton KT, Koob GF (1993). Microinjection of corticotropin releasing factor antagonist into the central nucleus of the amygdala reverses anxiogenic-like effects of ethanol withdrawal. Brain Res 605: 25-32.

Rivier C, Bruhn T, Vale W (1984). Effect of ethanol on the hypothalamic-pituitary-adrenal axis in the rat: role of corticotrophin-releasing factor (CRF). J Pharmacol Exp Ther 229: 127-131.

Rodd-Henricks ZA, Bell RL, Kuc KA, Murphy JM, McBride WJ, Lumeng L et al (2001). Effects of concurrent access to multiple ethanol concentrations and repeated deprivations on alcohol intake of alcohol-preferring rats. Alcoholism Clin Exp Res 25: 1140-1150.

Rodd-Henricks ZA, McKinzie DL, Shaikh SR, Murphy JM, McBride WJ, Lumeng $\mathrm{L}$ et al (2000). Alcohol deprivation effect is prolonged in the alcohol preferring (P) rat after repeated deprivations. Alcoholism Clin Exp Res 24: 8-16.

Sams-Dodd F (1995). Automation of the social interaction test by a video-tracking system: behavioral effects of repeated phencyclidine treatment. J Neurosci Methods 59: 157-167.

Sinclair JD (1972). The alcohol-deprivation effect: influence of various factors. Quat J Stud Alcohol 33: 769-782.

Sinha R (2001). How does stress increase risk of drug abuse and relapse. Psychopharmacology 158: 343-359.

Sinha R, O'Malley SS (1999). Craving for alcohol: findings from the clinic and the laboratory. Alcohol Alcoholism 34: 223-230.

Skerritt JH, Macdonald RL (1983). Benzodiazepine RO 15-1788: electrophysiological evidence for partial agonist activity. $\mathrm{Neu}$ rosci Lett 43: 321-326.

Spencer RL, McEwen BS (1990). Adaptation of the hypothalamicpituitary-adrenal axis to chronic ethanol stress. Neuroendocrinology 52: 481-489.

Ulrichsen J, Haugbol S, Brandt CF, Allerup P, Hemmingsen R (1998). Irreversibility of kindled alcohol-withdrawal behaviour in rats. Alcohol Alcoholism 33: 230-243.

Wafford KA, Thompson SA, Thomas D, Sikela J, Wilcox AS, Whiting PJ (1996). Functional characterization of human gamma-aminobutyric $\operatorname{acid}_{\mathrm{A}}$ receptors containing the alpha 4 subunit. Mol Pharmacol 50: 670-678. 
Wallace JE, Dahl EV (1966). Rapid vapor phase method for determining ethanol in blood and urine by gas chromatography. Am J Clin Pathol 46: 152-154.

Weiss F (2002). The role of CRF in craving and relapse. Pharmacologist 44: SA3.

Weiss M, Tikhonov D, Buldakova S (2002). Effect of flumazenil on $\mathrm{GABA}_{\mathrm{A}}$ receptors in isolated rat hippocampal neurons. Neurochem Res 27: 1605-1612.
Young RM, Oei TP, Knight RG (1990). The tension reduction hypothesis revisited: an alcohol expectancy perspective. $\mathrm{Br} J$ Addict 85: 31-40.

Zorrilla EP, Valdez GR, Weiss F (2001). Changes in levels of regional CRF-like immunoreactivity and plasma corticosterone during protracted drug withdrawal in dependent rats. Psychopharmacology 158: 374-381. 